\title{
Pengaruh Disiplin Kerja dan Motivasi Terhadap Kinerja Serta Dampaknya Terhadap Kepuasan Kerja (Survey Pada Pegawai Kantor Kecamatan Sungai Raya Kab. Kubu Raya)
}

\author{
${ }^{1}$ Jumardi Budiman, ${ }^{2}$ Steven \\ ${ }^{1}$ Universitas Tanjungpura, Pontianak, Indonesia \\ ${ }^{2}$ Sekolah Tinggi Ilmu Ekonomi Indonesia, Pontianak, Indonesia \\ Email : ${ }^{1}$ jumardib@fkip.untan.ac.id
}

(Diterima: Juli 2021; Direvisi: Juli 2021; Dipublikasikan: September 2021)

\begin{abstract}
ABSTRAK
Penelitian ini bertujuan untuk mengetahui pengaruh disiplin kerja dan motivasi terhadap kinerja serta dampaknya terhadap kepuasan kerja, dimana kinerja sebagai variabel intervening. Berdasarkan penelitian sebelumnya dan dikaitan dengan teori pendukung yang dikemukakan oleh para ahli dengan menggunakan program SPSS sebagai alat pengolah data statistik. Jenis penelitian ini yaitu assosiative research merupakan jenis penelitian yang bertujuan mengetahui pola hubungan antar variabel sebagai penguji hipotesa. Penelitian ini dilakukan di kantor kecamatan Sungai Raya, dengan semua populasi di jadikan sampel yaitu 20 orang seluruh pegawai kantor kecamatan Sungai Raya, dengan teknik analisis data menggunakan analisis jalur (Path Analysis).

Berdasarkan pengolahan data menggunakan analisis jalur, terbukti bahwa disiplin kerja dan motivasi berpengaruh terhadap kinerja pegawai dan disiplin kerja juga berpengaruh positif dan signifikan terhadap kepuasan kerja pegawai kecamatan Sungai Raya dengan kinerja pegawai sebagai variabel intervening.

\section{Kata Kunci: Disiplin Kerja, Motivasi, Kinerja, Kepuasan Kerja}




\section{PENDAHULUAN}

Berdasarkan Undang-undang Nomor 5 Tahun 2014 tentang ASN. Aparatur Sipil Negara (ASN) adalah profesi bagi pegawai negeri sipil dan pegawai pemerintah dengan perjanjian kerja yang bekerja pada instansi pemerintah.Untuk mencapai tujuan tersebut, maka dibutuhkan sumber daya aparatur atau yang lebih dikenal ASN (aparatur sipil negara) yang berkualitas. Sumber daya manusia merupakan faktor yang paling menentukan dalam setiap organisasi karena disamping sumber daya manusia sebagai kekuatan tapi juga merupakan faktor penentu utama dalam tercapainya tujuan organisasi. Pegawai merupakan salah satu aset terpenting di dalam suatu organisasi,karena itu sebagai pegawai juga dituntut untuk mempunyai sikap mental, tekad dan semangat, kedisiplinan serta memiliki kinerja yang tinggi agar apa yang dilaksanakan dalam tugas berjalan sesuai dengan rencana dan kebutuhan organisasi.

Dalam hal ini peneliti juga telah melakukan wawancara dan observasi kepada beberapa pegawai yang bekerja dikantor Kecamatan Sungai Raya. Berdasarkan hasil pra penelitian tersebut maka peneliti memperoleh data dan informasi terkait variabel peneliti. Salah satu informasi yang peneliti peroleh adalah bahwa dikantor Kecamatan Sungai Raya memiliki pegawai yang berjumlah 20 orang. Tercapainya tujuan suatu lembaga atau organisasi tidak hanya tergantung pada peralatan modern, sarana dan prasarana yang lengkap, tetapi justru lebih tergantung pada manusia (pegawai) yang melaksanakan pekerjaan tersebut.
Oleh karena itu pada lingkungan Kecamatan Sungai Raya, pegawai yang berkualitas adalah pegawai yang melaksanakan pekerjaannya dan mampu memberikan hasil kerja yang baik atau mempunyai disiplin tinggi yang dibutuhkan oleh instansi untuk mencapai tujuan dan hasil produksi yang tinggi. Untuk itu Kantor Kecamatan Sungai Raya berupaya mendapatkan pegawai yang terlibat dalam kegiatan yang tentunya dapat menciptakan kinerja yang baik dalam mencapai target yang telah ditetapkan oleh organisasi.

Kinerja pada umumnya diartikan sebagai kesuksesan seseorang dalam melaksanakan suatu pekerjaan Menurut Mangkunegara

(2001:67) Kinerja adalah hasil kerja yang secara kualitas yang telah dicapai oleh seorang karyawan atau pegawai dalam mengemban tugasnya sesuai dengan tanggung jawab yang telah diberikan kepadanya.

Menurut Hasibuan (2006:444) disiplin kerja adalah kesadaran dan kerelaan seseorang dalam menaati semua peraturan perusahaan dan norma-norma social yang berlaku.

Untuk memenuhi standar kinerja yang telah ditetapkan oleh Camat Sungai Raya tersebut maka pegawai dituntut untuk memiliki disiplin yang tinggi dalam melakukan suatu pekerjaan. Akan tetapi peraturan tersebut tidak sepenuhnya diikuti oleh pegawai terutama dalam hal kehadiran dikantor.Kedisiplinan dikantor Kecamatan Sungai Raya dinilai masih belum maksimal terutama dalam hal kehadiran karena masih terdapat pegawai yang tidak masuk kerja tiap bulannya.

Motivasi diartikan suatu sikap (attitude) pimpinan dan karyawan 
terhadap situasi kerja (situation) di lingkungan organisasinya. Mereka yang bersikap positif (pro) terhadap situasi kerjanya akan menunjukkan motivasi kerja tinggi dan sebaliknya jika mereka bersikap negatif (contra) terhadap situasi kerjanya akan menunjukkan motivasi kerja yang rendah. Situasi kerja yang dimaksud mencakup antara lain hubungan kerja, fasilitas kerja, iklim kerja, kebijakan pimpinan, pola kepemimpinan kerja dan kondisi kerja.

Faktor lain yang dapat mempengaruhi kinerja pegawai adalah kepuasan kerja. Kepuasan kerja mencerminkan perasaan seseorang terhadap pekerjaannya dan merupakan peranan penting dalam rangka menciptakan kinerja yang optimal. Ketika seseorang mendapatkan kepuasan dalam bekerja maka ia akan berupaya semaksimal mungkin dengan kemampuannya untuk menyelesaikan pekerjaannya, sehingga produktivitas dan kinerja pegawai akan meningkat secara optimal

\section{TINJAUAN PUSTAKA}

\section{Disiplin Kerja}

Menurut Rivai (2014) disiplin kerja adalah suatu alat yang digunakan para manajer untuk berkomunikasi dengan karyawan agar mereka bersedia untuk mengubah suatu perilaku dan untuk meningkatkan kesadaran juga kesediaan seseorang agar menaati semua peraturan dan norma sosial yang berlaku di suatu perusahaan.

\section{Motivasi}

Menurut Mangkunegara (2016) motivasi adalah kondisi atau energi yang menggerakkan diri karyawan yang terarah dan tertentu untuk mencapai tujuan organisasi.

\section{Kinerja}

Menurut Mangkunegara (2016) kinerja adalah hasil kerja secara kualitas dan kuantitas yang dicapai oleh seorang pegawai dalam melaksanakan tugasnya sesuai dengan tanggung jawab yang diberikan kepadanya.

4. Kepuasan Kerja

Kepuasan kerja adalah tingkat perasaan menyenangkan yang diperoleh dari penilaian pekerjaan seseorag atau pengalaman kerja Watson (2011).

\section{Hipotesis}

H1: Disiplin kerja berpengaruh positif terhadap kinerja pegawai

$\mathrm{H} 2$ : Motivasi berpengaruh positif terhadap kinerja pegawai

H3: Kinerja pegawai berpengaruh positif terhadap kepuasan kerja.

H4: Disiplin kerja berpengaruh positif terhadap kepuasan kerja pegawai.

H5 : Motivasi berpengaruh positif terhadap kepuasan kerja pegawai.

\section{METODE PENELITIAN}

Penelitian ini dilakukan pada kantor kecamatan Sungai Raya Kabupaten Kubu Raya. Adapun sampel yang diambil adalah sebesar 20 responden, yang dimana semua pegawai dalam populasi dijadikan sampel. Jenis penelitian ini yaitu assosiative research merupakan jenis penelitian yang bertujuan mengetahui pola hubungan antar variabel sebagai penguji hipotesa, dengan teknik 
analisis data menggunakan analisis jalur (Path Analysis).

\section{HASIL PENELITIAN}

\section{Uji Reliabilitas dan Validitas Data}

Dalam analisis kuantitatif ini dilakukan pengujian validitas dan reliabilitas data mengenai butir-butir kuesioner melalui skor data yang telah diperoleh dari jawaban responden. Uji reliabilitas dan validitas dilakukan dengan menggunakan program SPSS Versi 25.

jika $\begin{array}{rr}\text { Butir kuesioner dikatakan valid } \\ \text { kuesioner mampu }\end{array}$ mengungkapkan sesuatu yang akan diukur oleh kuesioner tersebut. Untuk menentukan valid tidaknya kuesioner dalam penelitian menggunakan perbandingan antara corrected itemtotal correlation dengan koefisien korelasi yang ditentukan. Sugiyono dan wibowo (2004), Suyuthi (2005) dan Sugiyono (2004) dalam Sujianto (2007:99) menyatakan bila korelasi tiap faktor positif dan besarnya $0,3 \mathrm{ke}$ atas maka faktor tersebut merupakan construct yang kuat. Dengan demikian butir kuesioner dikatakan valid jika corrected item-total correlation lebih besar dari 0,3 dan sebaliknya jika corrected item-total correlation lebih kecil dari 0,3 maka butir pernyataan dikatakan tidak valid.
Tabel 1

Hasil Uji Reliabiitas

\begin{tabular}{|c|c|c|}
\hline Variabel & $\begin{array}{c}\text { Cronbach's } \\
\text { Alpha }\end{array}$ & $\begin{array}{c}\text { N of } \\
\text { items }\end{array}$ \\
\hline $\begin{array}{c}\text { Disiplin } \\
\text { Kerja }\end{array}$ & 0,853 & 7 \\
\hline Motivasi & 0,885 & 7 \\
\hline $\begin{array}{c}\text { Kinerja } \\
\text { Pegawai }\end{array}$ & 0,938 & 7 \\
\hline $\begin{array}{c}\text { Kepuasan } \\
\text { Kerja }\end{array}$ & 0,832 & 7 \\
\hline
\end{tabular}

Sumber: SPSS 25.00

Berdasarkan hasil pengujian reliabilitas di atas, diketahui angka Cronbach alpha adalah dimana lebih besar dari nilai minimal 0,6 sehingga dapat disimpulkan bahwa instrument penelitian dapat dikatakan reliabel.

- Hasil uji validitas dari 7 item disiplin kerja, semua dinyatakan valid karena semua hasil ke 7 item tersebut memiliki nilai corrected item-total correlation lebih dari 0,3

- Hasil uji validitas dari 7 item motivasi, semua dinyatakan valid karena semua hasil dari 7 item tersebut memiliki nilai corrected item-total correlation lebih dari 0,3 .

- Hasil uji validitas dari 7 item kinerja pegawai semua dinyatakan valid karena semua hasil dari 7 item tersebut memiliki nilai corrected item-total correlation lebih dari 0,3 .

- Hasil uji validitas dari 7 item kepuasan kerja semua dinyatakan valid karena semua hasil dari 7 item tersebut memiliki nilai corrected item-total correlation lebih dari 0,3 . 


\section{Hasil Uji Hipotesis dan Pembahasan}

Tabel 2 Uji secara Parsial Pengaruh Disiplin Kerja dan Motivasi Terhadap Kinerja Pegawai Coefficients $^{\mathbf{a}}$

\begin{tabular}{|c|c|c|c|c|c|c|}
\hline \multirow{2}{*}{\multicolumn{2}{|c|}{ Model }} & \multicolumn{2}{|c|}{$\begin{array}{c}\text { Unstandardized } \\
\text { Coefficients }\end{array}$} & \multirow{2}{*}{$\begin{array}{c}\text { Standardized } \\
\text { Coefficients }\end{array}$} & \multirow[b]{2}{*}{$\mathrm{t}$} & \multirow[b]{2}{*}{ Sig. } \\
\hline & & $\mathrm{B}$ & Std. Error & & & \\
\hline \multirow[t]{3}{*}{1} & (Constant) & -8.640 & 7.433 & & -1.162 & .261 \\
\hline & Disiplin_Kerja & .626 & .226 & .592 & 2.776 & .013 \\
\hline & Motivasi & .125 & .125 & 213 & 1.000 & .031 \\
\hline
\end{tabular}

Dependent Variable: Kinerja_Pegawai Sumber : SPSS 25.00

Pada bagian table Coefficients dapat diketahui bahwa secara parsial nilai signifikansi dari variabel disiplin kerja 0,013 dan motivasi adalah

Tabel 3 Uji secara Parsial Pengaruh Disiplin Kerja, Motivasi, dan Kinerja Terhadap Kepuasan Kerja

Coefficients $^{\mathrm{a}}$

\begin{tabular}{|c|c|c|c|c|c|c|}
\hline & & \multicolumn{2}{|c|}{$\begin{array}{c}\text { Unstandardized } \\
\text { Coefficients }\end{array}$} & \multirow{2}{*}{$\begin{array}{c}\text { Standardized } \\
\text { Coefficients } \\
\text { Beta }\end{array}$} & \multirow[b]{2}{*}{$\mathrm{t}$} & \multirow[b]{2}{*}{ Sig. } \\
\hline \multicolumn{2}{|c|}{ Model } & B & Std. Error & & & \\
\hline \multirow[t]{4}{*}{1} & (Constant) & -8.640 & 7.433 & & -1.162 & 261 \\
\hline & Disiplin_Kerja & .626 & .226 & .592 & 2.776 & .013 \\
\hline & Motivasi & .125 & .125 & .213 & 1.000 & .031 \\
\hline & Kinerja & .524 & 244 & .234 & 1.700 & .000 \\
\hline
\end{tabular}

Dependent Variable: Kepuasan_Pegawai

Sumber : SPSS 25.00

Pada bagian table Coefficients dapat diketahui bahwa secara parsial nilai signifikansi dari variabel disiplin kerja 0,01, motivasi adalah 0.031., dan kinerja adalah 0.000. Dari nilai
0.031. Dari nilai tersebut dapat disimpulkan bahwa disiplin kerja dan motivasi berpengaruh signifikan terhadap kinerja pegawai karena besarnya nilai adalah lebih kecil dari 0,05 . disiplin kerja, motivasi, dan kinerja berpengaruh signifikan terhadap kepuasan kerja karena besarnya nilai adalah lebih kecil dari 0,05. tersebut dapat disimpulkan bahwa

\section{Uji secara Simultan}

Tabel 4. Uji ANOVA

ANOVA $^{a}$

\begin{tabular}{|l|l|r|r|r|r|c|}
\hline \multicolumn{2}{|l|}{ Model } & \multicolumn{1}{c|}{$\begin{array}{c}\text { Sum of } \\
\text { Squares }\end{array}$} & df & $\begin{array}{c}\text { Mean } \\
\text { Square }\end{array}$ & \multicolumn{1}{c|}{ F } & \multicolumn{1}{c|}{ Sig. } \\
\hline \multirow{2}{*}{1} & Regression & 180.348 & 2 & 90.174 & 10.883 & $.001^{\text {b }}$ \\
\cline { 2 - 7 } & Residual & 140.852 & 17 & 8.285 & & \\
\cline { 2 - 7 } & Total & 321.200 & 19 & & & \\
\hline
\end{tabular}

a. Dependent Variable: Kepuasan_Kerja

b. Predictors: (Constant), Kinerja_Pegawai, Motivasi, Disiplin_Kerja

Sumber : Output SPSS 25.00 
Pada bagian table Coefficients dapat diketahui bahwa secara anova nilai signifikansi adalah sebesar 0.001 yang artinya sig $<0.005$. Dari nilai tersebut dapat disimpulkan bahwa disiplin kerja, motivasi, dan kinerja berpengaruh signifikan terhadap kepuasan kerja secara simultan.

\section{Uji Koefesien Determinasi}

Tabel 5 Uji Koefesien Determinasi

Model Summaryb

\begin{tabular}{|c|c|c|c|c|c|c|c|c|c|c|}
\hline \multirow[b]{2}{*}{ Model } & \multirow[b]{2}{*}{$\mathrm{R}$} & \multirow[b]{2}{*}{$\begin{array}{c}\mathrm{R} \\
\text { Square }\end{array}$} & \multirow[b]{2}{*}{$\begin{array}{c}\text { Adjusted } \\
\text { R } \\
\text { Square }\end{array}$} & \multirow[b]{2}{*}{$\begin{array}{l}\text { Std. } \\
\text { Error of } \\
\text { the } \\
\text { Estimate }\end{array}$} & \multicolumn{5}{|c|}{ Change Statistics } & \multirow[t]{2}{*}{$\begin{array}{l}\text { Durbin- } \\
\text { Watson }\end{array}$} \\
\hline & & & & & $\begin{array}{c}\text { R } \\
\text { Square } \\
\text { Change }\end{array}$ & $\begin{array}{c}\mathrm{F} \\
\text { Change }\end{array}$ & df1 & df2 & $\begin{array}{c}\text { Sig. F } \\
\text { Change }\end{array}$ & \\
\hline 1 & $.749^{a}$ & .561 & .510 & 2.878 & .561 & 10.883 & 2 & 17 & .001 & 1.982 \\
\hline
\end{tabular}

a. Predictors: (Constant), Motivasi, Disiplin_Kerja, Kinerja_Pegawai

b. Dependent Variable: Kepuasan_Kerja

Sumber : Output SPSS 25.00

Besarnya nilai $\mathrm{R}^{2}$ atau $\mathrm{R}$ Square yang terdapat pada tabel Summary adalah sebesar 0,561, hal ini menunjukkan bahwa kontribusi atau sumbangan pengaruh disiplin kerja, motivasi, dan kinerja pegawai terhadap kepuasan kerja adalah sebesar $56,1 \%$ sedangkan $43,9 \%$ lainnya merupakan kontribusi dari variabel lain yang tidak dimasukkan dalam penelitian.

\section{PENUTUP}

\section{Simpulan}

1. Ada pengaruh yang signifikan dari variabel disiplin kerja terhadap kinerja pegawai. Uji pengaruh variabel disiplin kerja terhadap kinerja pegawai dapat dilihat pada tabel 2 (nilai $\rho=0,013<0,05$ ). Karena $\rho$ value $<\alpha$ maka terdapat pengaruh yang signifikan dari variabel disiplin kerja terhadap kinerja pegawai.

2. Ada pengaruh yang signifikan dari variabel motivasi terhadap kinerja pegawai. Uji pengaruh variabel disiplin kerja terhadap kinerja pegawai dapat dilihat pada tabel 2 (nilai $\rho=0,031<0,05$ ). Karena $\rho$ value $<\alpha$ maka terdapat pengaruh yang signifikan dari variabel motivasi terhadap kinerja pegawai.

3. Ada pengaruh yang signifikan dari variabel kinerja pegawai terhadap kepuasan. Uji pengaruh variabel disiplin kerja terhadap kinerja pegawai dapat dilihat pada tabel 3 (nilai $\rho=0,000<0,05$ ). Karena $\rho$ value $<\alpha$ maka terdapat pengaruh yang signifikan dari variabel kinerja pegawai terhadap kepuasan kerja.

4. Ada pengaruh yang signifikan dari variabel disiplin kerja, motivasi, dan kinerja terhadap kepuasan kerja. Uji pengaruh variabel disiplin kerja terhadap kinerja pegawai dapat dilihat pada tabel 4 (nilai $\rho=0,001<0,05$ ). Karena $\rho$ value $<\alpha$ maka terdapat pengaruh yang signifikan dari variabel disiplin kerja, motivasi, dan kinerja secara simultan terhadap kepuasan kerja.

\section{Saran}

Usaha yang dapat dilakukan dalam meningkatkan kinerja pegawai sehingga berdampak pada kepuasan 
pegawai, diantaranya adalah meningkatkan indikator disiplin kerja, yaitu dengan ketaatan pada standar kerja, meningkatkan motivasi pegawai dengan memberikan pelatihan dan seminar yang dimana memberikan dampak jangka panjang terhadap kinerja sehingga dapat menciptakan kepuasan pegawai itu sendiri.

\section{DAFTAR PUSTAKA}

Colquiit, J.A., Lepine, A. J., \& Wesson (2011) Organizational Behavior. New York: Mc. Graw Hill.

Hasibuan, M.S.P. (2016), Manajemen Sumber Daya Manusia, Edisi Revisi, Penerbit PT. Bumi Aksara, Jakarta.

Kristianti, L. S., et al (2021). Pengaruh Motivasi Dan Disiplin Kerja Terhadap Kinerja Pegawai Pada Dinas Pariwisata Purwakarta. Jurnal
Ilmiah PERKUSI, 1(1), 101109.

Mangkunegara, A.P. (2015). Evaluasi Kinerja SDM, Penerbit Refika Aditama, Bandung.

Nisfianoor, Muhammad. (2009). Pendekatan Statistika Modern, Penerbit Salemba Huamanika, Jakarta.

Nurjaya, N., et al (2021). Pengaruh Etos Kerja Dan Disiplin Kerja Terhadap Kinerja Pegawai Pada Dinas Kehutanan Dan Perkebunan Kota Bogor. JENIUS (Jurnal Ilmiah Manajemen Sumber Daya Manusia), 4(2), 172-184.

Sedarmayanti. (2015). Sumber Daya Manusia dan Produktivitas Kerja. Bandung.

Sugiyono. (2007). Metode Penelitian Bisnis, Edisi Ketujuh, Penerbit CV. Alfabeta, Bandung.

Supriyanto. (2009). Metodologi Riset Bisnis, Penerbit PT Indeks, Jakarta. 